(C) Asian Fisheries Society

ISSN 0116-66514

E-ISSN: 2073-3720

https://doi.org/10.33997/j.afs.2010.23.4.006

\title{
Performance of a closed recirculating system with foam separation, nitrification and denitrification units for intensive culture of kuruma shrimp, Marsupenaeus japonicus: a bench scale study
}

\author{
Yoshihiro Suzuki $^{1 *}$, Tsuyoshi Takeshima ${ }^{1}$, Thoru Mekata ${ }^{2}$, Tomoya Kono ${ }^{2}$, \\ Masahiro Sakai $^{2}$, Toshiaki Itami ${ }^{2}$ and Toshiroh Maruyama ${ }^{1}$ \\ ${ }^{1}$ Department of Civil and Environmental Engineering, Faculty of Engineering \\ University of Miyazaki, Miyazaki 889-2192, Japan \\ ${ }^{2}$ Faculty of Agriculture, University of Miyazaki, Miyazaki 889-2192, Japan
}

\begin{abstract}
The development of a closed recirculating aquaculture system that does not discharge effluents would reduce a large amount of pollutant load on aquatic bodies. In this study,kuruma shrimp Marsupenaeus japonicus were reared in a closed recirculating system (total water volume, $1.3 \mathrm{~m}^{3}$ ), which consisted of a culture tank (area, $1.2 \mathrm{~m}^{2}$ ), a foam separation unit, a nitrification unit and a denitrification unit. The foam separation unit has an inhalation-type aerator and supplies air bubbles to the culture water. The shrimp used in the test $\left(0.8 \mathrm{~g}\right.$.individual $^{-}$ ${ }^{1}$ ) were judged in advance to be free of the white spot disease virus (WSDV) by the method of loop-mediated isothermal amplification (LAMP). The growth of shrimp, which were fed a commercial diet, was satisfactory, with the average weight increases of up to 11 times in 4.5 months. The individual density at the end of the culture period was 51 individuals $\mathrm{m}^{-2}$. The foam separation unit maintained oxygen saturation in the water used for rearing at $101 \%$. Furthermore, contaminants such as suspended solids, chromaticity substances and bacteria absorbed on the stable foam were removed from the culture water by foam separation. The turbidity in culture water was kept at less than two units. Total ammonia-nitrogen (TAN) and nitrite $\left(\mathrm{NO}_{2}-\mathrm{N}\right)$ oxidation were accomplished rapidly and simultaneously in the nitrification unit. TAN and $\mathrm{NO}_{2}-\mathrm{N}$ concentrations were kept at less than $0.4 \mathrm{mg}-\mathrm{N}^{-1}$ and $0.02 \mathrm{mg}-\mathrm{NL}^{-1}$, respectively. When the denitrification process was operated, nitrate $\left(\mathrm{NO}_{3}-\mathrm{N}\right)$ that accumulated in the culture water $\left(20 \mathrm{mg}-\mathrm{N}^{\cdot} \mathrm{L}^{-1}\right)$ was reduced to $4 \mathrm{mg}-\mathrm{N}^{\cdot} \mathrm{L}^{-1}$. Based on these results, the intensive aquaculture of kuruma shrimp can be achieved using a closed recirculating system under virusfree conditions without emission.
\end{abstract}

*Corresponding author. E-mail address: suzuki@civil.miyazaki-u.ac.jp 


\section{Introduction}

The technology of a recirculating aquaculture system with a high fish density has been developed (Bovendeur et al. 1987; Heinsbroek and Kamsta 1990; van Rijn and Rivera 1990; $\mathrm{Ng}$ et al. 1992; Knosche 1994; Honda et al. 1994; Arbiv and van Rijn 1995; van Rijn 1996; Geiner and Timmous 1998; Yoshino et al. 1999) and the remarkably high productivity and energy efficiency of such a system have become possible (Blancheton 2000). In addition, shrimp, which has the highest demand in the global seafood market, is now produced in closed recirculating systems (Otoshi et al. 2003). However, the frequency of changing rearing water per day is from 5 to $100 \%$ in general, thereby having minimal effect on the reduction in pollutant load. In our study that examined the amount of pollution drained from inland aquaculture farms in Japan, it was found that the type of fish being cultivated made minimal difference. On average, the load per unit of cultured fish was $0.8 \mathrm{~kg}-\mathrm{N}^{\bullet t}-\mathrm{fish}^{-1} \mathrm{day}^{-1}$ and $0.1 \mathrm{~kg}-\mathrm{P} \mathrm{t}^{-} \mathrm{fish}^{-1} \mathrm{day}^{-1}$ (Maruyama and Suzuki 1998). This pollutant load corresponded to 73 persons ${ }^{-1}-$ fish $^{-1}$ assuming that the human nitrogen load is equivalent to $11 \mathrm{~g}-\mathrm{N}$ person ${ }^{-1} \cdot$ day $^{-1}$. It assumed that the load of shrimp culture is equal to that of fish culture. While the aquaculture industry supplies food and livelihood to many, it is likewise a bane to aquatic environments. Particularly, the expansion of shrimp farm affects the pollution load increase, the degradation of the coastal environment and valuable area such as mangrove forests (Mumby et al. 2004).

Recently, the aquaculture industry is likewise urged to convert to a new system that introduces the concept of zero emission and this requires the development of a closed recirculating system using innovative technology for fish production. Zeroemission aquaculture system in an actual shrimp farm has not yet been developed. However, if intensive shrimp culture in a perfectly closed recirculating system becomes technically possible, the development of zero-emission systems can be realized.

With the combined aim of increased fish production and reduced nutrient load in aquatic environments, we have advanced the development of a zero-emission system composed of foam separation, nitrification and denitrification units. Culture trials of Japanese flounder in seawater (Maruyama et al. 1998; Suzuki et al. 2000) and eel in fresh water (Suzuki et al. 2003) were carried out using this almost perfectly closed system. The survival rate was very high, that is, more than 3 months despite the high fish density. The advantage of this system is that it is equipped with an effective foam separation unit as part of its main purification process. Oxygen supply, removal of suspended substances and deaeration can be achieved simultaneously by the foam separation process (Maruyama et al. 1991; Maruyama et al. 1996). By applying the principles of the fish culture system, we tried the development of a closed recirculating 
system for culturing kuruma shrimp. An ideal aquaculture system is one which purifies the rearing water while obtaining high biomass productivity. In this study, shrimp growth, function of each water treatment process and load reduction were examined.

\section{Materials and Methods}

\section{System description}

A closed recirculating system with foam separation, nitrification and denitrification units is shown in Fig.1. This system consisted of a shrimp rearing tank (water volume $0.7 \mathrm{~m}^{3}$; water surface area $\left.1.2 \mathrm{~m}^{2}\right)$, a foam separation tank $\left(0.2 \mathrm{~m}^{3}\right)$ equipped with an inhalation-type aerator $(200 \mathrm{~V}, 0.2 \mathrm{kw})$, a nitrification tank $\left(0.16 \mathrm{~m}^{3}\right)$ and a denitrification tank $\left(0.22 \mathrm{~m}^{3}\right)$. The total amount of water in this system was 1.3 $\mathrm{m}^{3}$. A heater $(100 \mathrm{~V}, 1 \mathrm{kw}$ ) and a pH control pump (Iwaki Co., EH.W-PH, 5\% sodium hydrogen carbonate solution) for adjusting the conditions of the rearing water $\left(25^{\circ} \mathrm{C}\right.$ and $\mathrm{pH}$ 7.5) were set in the foam separation tank and a water conditioner was set on the recirculating pipe. First, sand filtered seawater was introduced to the system and one cycle was carried out for $15 \mathrm{~min}$ at $56 \mathrm{~L}^{\circ} \mathrm{min}^{-1}$. The rearing water was transported to the foam separation tank by a circulating pump and oxygen supply and foam separation processing were simultaneously carried out using this unit. The rearing water was then introduced into the nitrification tank with an up-flow style and the treated rearing water was returned to the rearing tank. The system was located indoors and the rearing tank was shielded from light.

The difference between fish and kuruma shrimp rearing is that kuruma shrimp lives in the sand during daytime. Therefore, the sand must be laid at the bottom of the rearing tank. The sand used in the rearing tank accumulated evacuated matters and residual feed and large amount of labor is required to clean the sand. To reduce the accumulation of polluted substances in the sand, the rearing tank was made with a double bottom and the rearing water was made to flow upward under the sand layer. Coral sand (grain size, $2 \mathrm{~mm}$ ) was used for this system.

The main core of this system for rearing water treatment was the foam separation unit (Suzuki et al. 2003), which was equipped with an inhalation-type aerator (Plesca Co., Japan). Surface-active materials in the rearing water were adsorbed on bubbles and the bubbles were carried to the water surface. Then, foam was generated on the water surface. The foam generated continuously was spontaneously removed from the foam duct placed at the upper part of the tank equipped with air exhaust. Furthermore, air bubbles were vigorously mixed into the water and oxygen was 
efficiently dissolved into the rearing water until it passed through the foam separation unit.

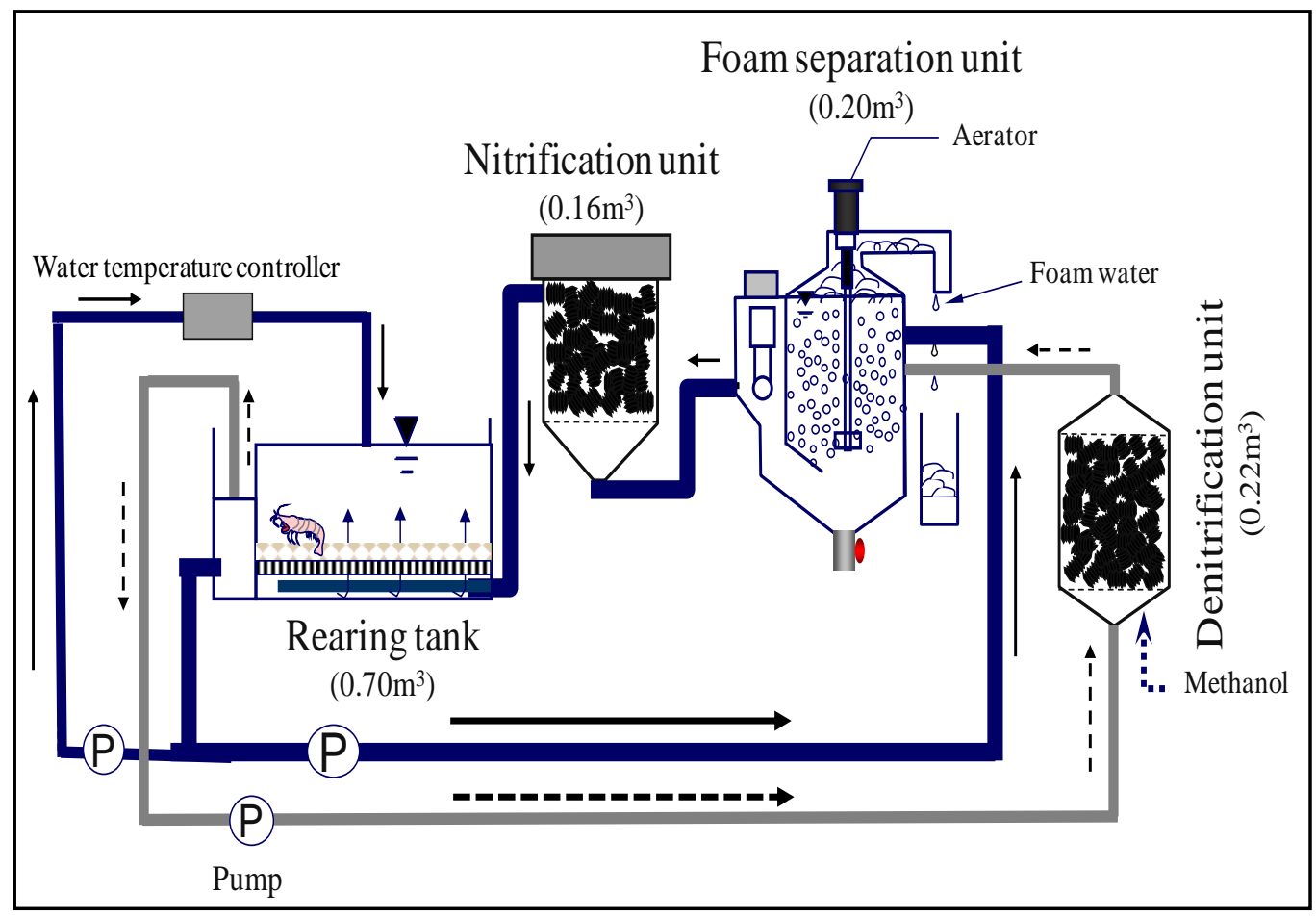

Fig. 1.Schematic diagram (not to scale) of the closed recirculating system with foam separation, nitrification and denitrification units.

A cylindrical medium made of polyethylene (Furukawa Electrician Industry Co., $14 \mathrm{~mm}$ diameter, $11 \mathrm{~mm}$ inside diameter, $14 \mathrm{~mm}$ length, 0.93 specific gravity) was used to fill the nitrification tank up to the $0.16 \mathrm{~m}^{3}$ (surface area $0.93 \mathrm{~m}^{2}$ ) mark. Nitrifying bacteria were immobilized onto the medium prior to the shrimp-rearing experiment.

In the denitrification process, a portion of the rearing water was made to flow into the denitrification tank using another line via a circulating pump. The same medium as that used in the nitrification process was used as the denitrification medium. The methanol dose tube was established at the midpoint of the inflow line to the denitrification tank and methanol was continuously injected by a metering pump (Iwaki Co., EH-B15) with an appropriate amount of methanol corresponding to five times the concentration of $\mathrm{NO}_{3}-\mathrm{N}$ in the rearing water. Then, the mixture of rearing water and methanol was introduced into the denitrification tank. Methanol injection was adjusted taking into account the $\mathrm{NO}_{3}-\mathrm{N}$ concentration in the rearing water every week. The 
treated water that passed through the denitrification tank was returned to the foam separation tank.

The above system was considered an almost perfectly closed system because water was added only to replace that which was lost to evaporation and foam generation.

\section{Shrimp rearing}

Juvenile kuruma shrimp M. japonicus (total gross weight 100 g, 125 individuals, about 0.8 gindividual $^{-1}$ ) were placed in the rearing tank. The shrimp used in the test were judged in advance to be free of the white spot disease virus (WSDV) by the method of loop-mediated isothermal amplification (LAMP) (Kono et al. 2004). Throughout the rearing experiment, the shrimp were fed a commercial diet (crude protein, above 51.0\%; oil, above 5.0\%; fiber, less than 5.0\%; ash, less than $22.0 \%$; calcium, above $0.5 \%$, phosphorus, above $0.080 \%$; Kyowahakko Co., Japan) daily. In the initial stage, $5 \mathrm{~g}$ of the feed was given once daily, every evening. Shrimp were cultured for 135 days.

\section{Analytical methods}

To determine the quality of rearing water, a sample was collected every 2 or 3 days from the rearing tank before feeding. Dissolved oxygen (DO), turbidity as kaolin standard (Mitsubishi Kagaku Co., SEP-PT-706D), total organic carbon (TOC, Shimadzu Co.,TOC-5000), color as cobalt platinum standard, absorbance at $260 \mathrm{~nm}$ (E260, Shimadzu Co., UV-2200), TAN (HACH Co., DR-2000), $\mathrm{NO}_{3}-\mathrm{N}$ (HACH Co., DR-2000), $\mathrm{NO}_{2}-\mathrm{N}(\mathrm{HACH}, \mathrm{DR}-2000)$, total nitrogen $(\mathrm{T}-\mathrm{N})$, phosphate $\left(\mathrm{PO}_{4}-\mathrm{P}\right)$ and total phosphorus (T-P) were analyzed. The standard platinum-cobalt method of measuring color was used, in which the unit of color is produced by $1 \mathrm{mg}-\mathrm{Pt}^{-1}$ in the form of chloroplatinate ion. The collapsed-foam water samples were also obtained and TOC, color, E260, suspended solids (SS), T-N and T-P were analyzed. The analytical methods followed that of the Japanese Industrial Standard (JIS K 0102) or HACH Co. analytical manual.

Nitrogen in the solid samples, such as feed, shrimp tissue, ecdysis shell and dried sludge, were analyzed using an elemental analyzer (CHNS.O Analyzer 2400, Perkin Elmer Co.). Phosphorus in solid matter was decomposed in a mixture of perchloric acid and nitric acid and analyzed in the same way as T-P in rearing water. 


\section{Results and Discussion}

\section{Growth of shrimp}

The shrimp growth during the experimental period (135 days) is shown in Fig. 2. Throughout the rearing period, the shrimp fed actively and their total weight increased over time.

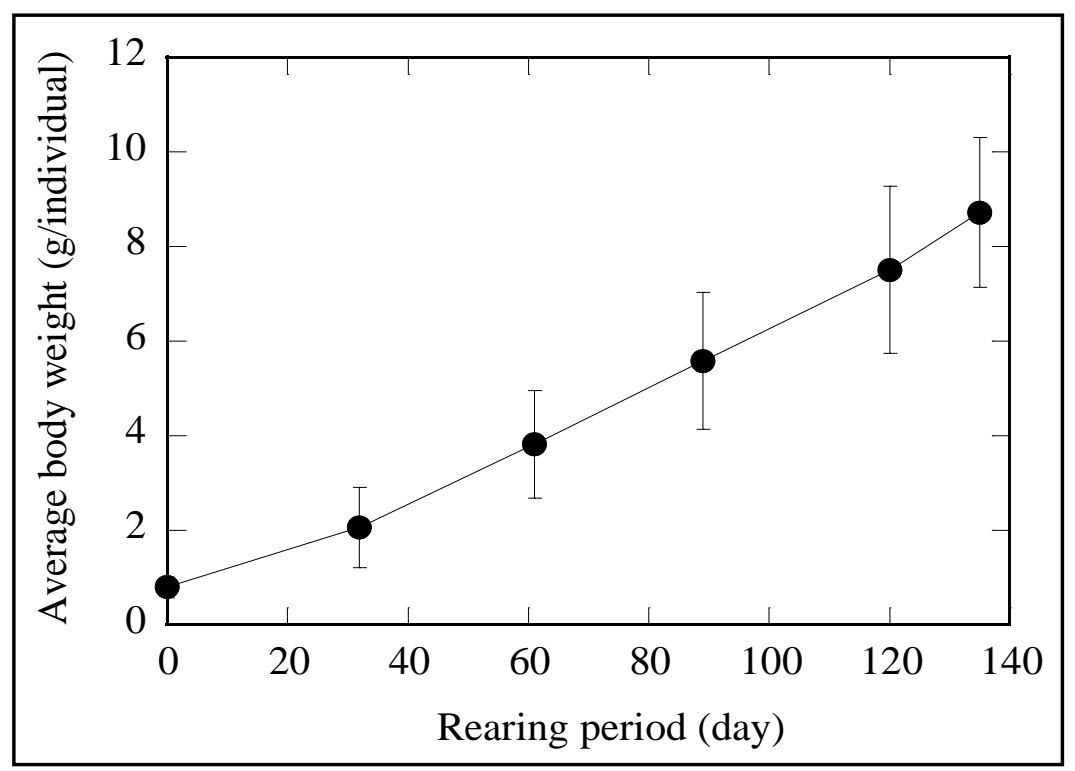

Fig. 2. Shrimp growth during the rearing period.

The individual weight increased from an average of $0.80 \mathrm{~g}$ to $8.72 \mathrm{~g}$ during the experimental period. The growth rate was $1.98 \mathrm{~g}^{\cdot} \mathrm{month}^{-1}$ and the rearing density was 51 individuals $\mathrm{m}^{-2}$ by the end of the study. Although there was no dead individual throughout the rearing period, total population decreased from 125 to 61 individuals. The survival rate through the trial was $49 \%$ because of cannibalism.

\section{Quality of rearing water}

The changes in DO of the rearing water are shown in Fig. 3. The oxygen saturation percentage was kept above approximately $101 \%$ throughout the experimental period.

The maximum and minimum DO concentrations were $7.0 \mathrm{mg} \cdot \mathrm{L}^{-1}$ and $6.0 \mathrm{mg} \cdot \mathrm{L}^{-}$ ${ }^{1}$, respectively, with a mean of $6.55 \mathrm{mg} \cdot \mathrm{L}^{-1}$. While this system does not provide an 
extraneous source of oxygen except for the aerator in the foam separation tank, a high DO concentration was properly maintained in the rearing water.

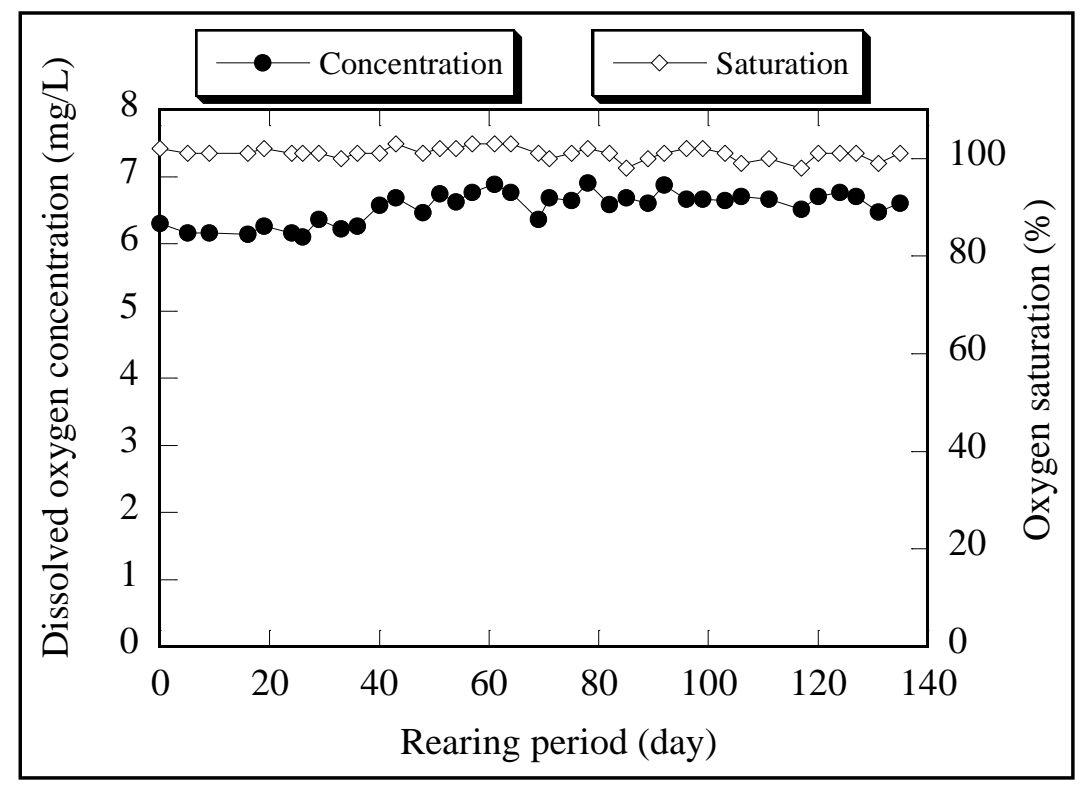

Fig. 3. Dissolved oxygen level in the rearing water.

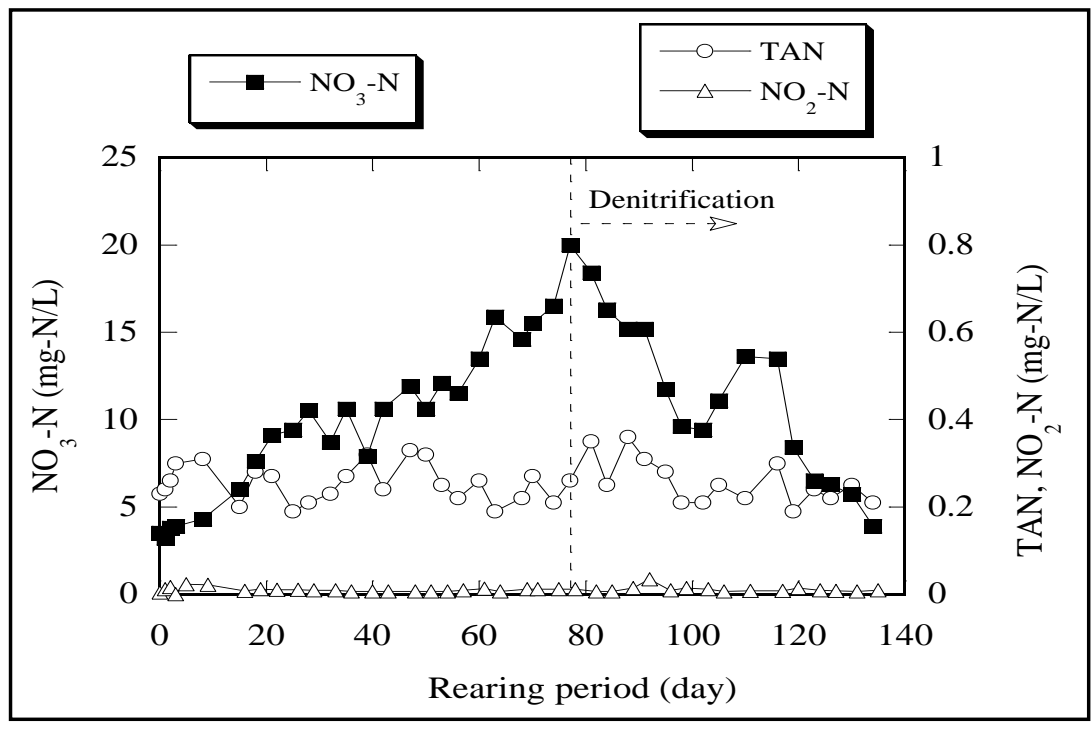

Fig. 4. Concentration of nitrogen compounds in the rearing water during the rearing period.

The changes in the concentrations of TAN, $\mathrm{NO}_{2}-\mathrm{N}$ and $\mathrm{NO}_{3}-\mathrm{N}$ in the rearing water are shown in Fig. 4. The TAN concentration was kept low throughout the study period at less than $0.4 \mathrm{mg}-\mathrm{NL}^{-1}$. The $\mathrm{NO}_{2}-\mathrm{N}$ concentration was maintained at a very 
low level less than $0.02 \mathrm{mg}-\mathrm{NL}^{-1}$ for 135 days. In contrast, $\mathrm{NO}_{3}-\mathrm{N}$ was formed via TAN oxidation in the absence of denitrification and $\mathrm{NO}_{3}-\mathrm{N}$ steadily accumulated in the rearing water. However, when the denitrification process was initiated on the 78th day, $\mathrm{NO}_{3}-\mathrm{N}$ concentration began to decrease after about 1 week and was reduced to $4 \mathrm{mg}-$ $\mathrm{N} \cdot \mathrm{L}^{-1}$ by the end of the study. In the period without denitrification, the cumulative amount of feed intake (x) and the amount of $\mathrm{NO}_{3}-\mathrm{N}(\mathrm{y})$ in the system showed a good correlation $(\mathrm{y}=0.031 \mathrm{x}, \mathrm{r}=0.934)$. For example, when $100 \mathrm{~g}$ of feed were given to the shrimp, $3.1 \mathrm{~g}$ of $\mathrm{NO}_{3}-\mathrm{N}$ accumulated continuously in the rearing water without denitrification process.

The fundamental parameters such as $\mathrm{pH}$, water temperature and salinity were kept at $8.0,28^{\circ} \mathrm{C}$ and $2.8 \%$, respectively throughout the trial.

\section{Characteristics of foam separation process}

The foam which concentrated the polluted substances was generated from the duct of the foam separation unit during the rearing period. The average quantity of water discharged per day was $293 \mathrm{~mL}(\mathrm{n}=36,0.02 \%$ per day, $0.293 \mathrm{~L}$. $1300 \mathrm{~L}=0.0002)$. Total volume of foam water was less than $40 \mathrm{~L}$ during the rearing period. It has been reported that foam generation of fish mucus is dependent on the concentrations of mucus and coexisting solvent ions (Suzuki et al. 2003). It was proven that the mucus substance acts on the foam separation process for not only fish rearing but also shrimp rearing.

The suspended solids were significantly concentrated in the separated foam water and the turbidity of the separated foam water was two orders of magnitude higher than that of the rearing water (Fig. 5). The turbidity of the rearing water was maintained in the range of 1-2 units, whereby almost no suspended substances could be observed. The turbidity in the foam water changed irregularly and varied from 50 to $600 \mathrm{mg} \cdot \mathrm{L}^{-1}$, making it necessary to remove suspended substances from the system by a foam separation process. Suspended solids was not analyzed in the rearing water since only small amounts were observed and that the turbidity of the rearing water was retained at less than 1.0 unit. Moreover, a brown material was significantly concentrated in the foam water. The color unit of the foam water (average, 369 units; $n=36$ ) was 100 to 1000 times higher than that of the rearing water (Fig. 5). The foam separation process was able to remove the color components, which are difficult to remove by biological treatment or physical filtration. Furthermore, an analysis of the effect of bacterial removal was undertaken (Fig. 6). The bacteria was concentrated markedly and suspended in the foam water. 


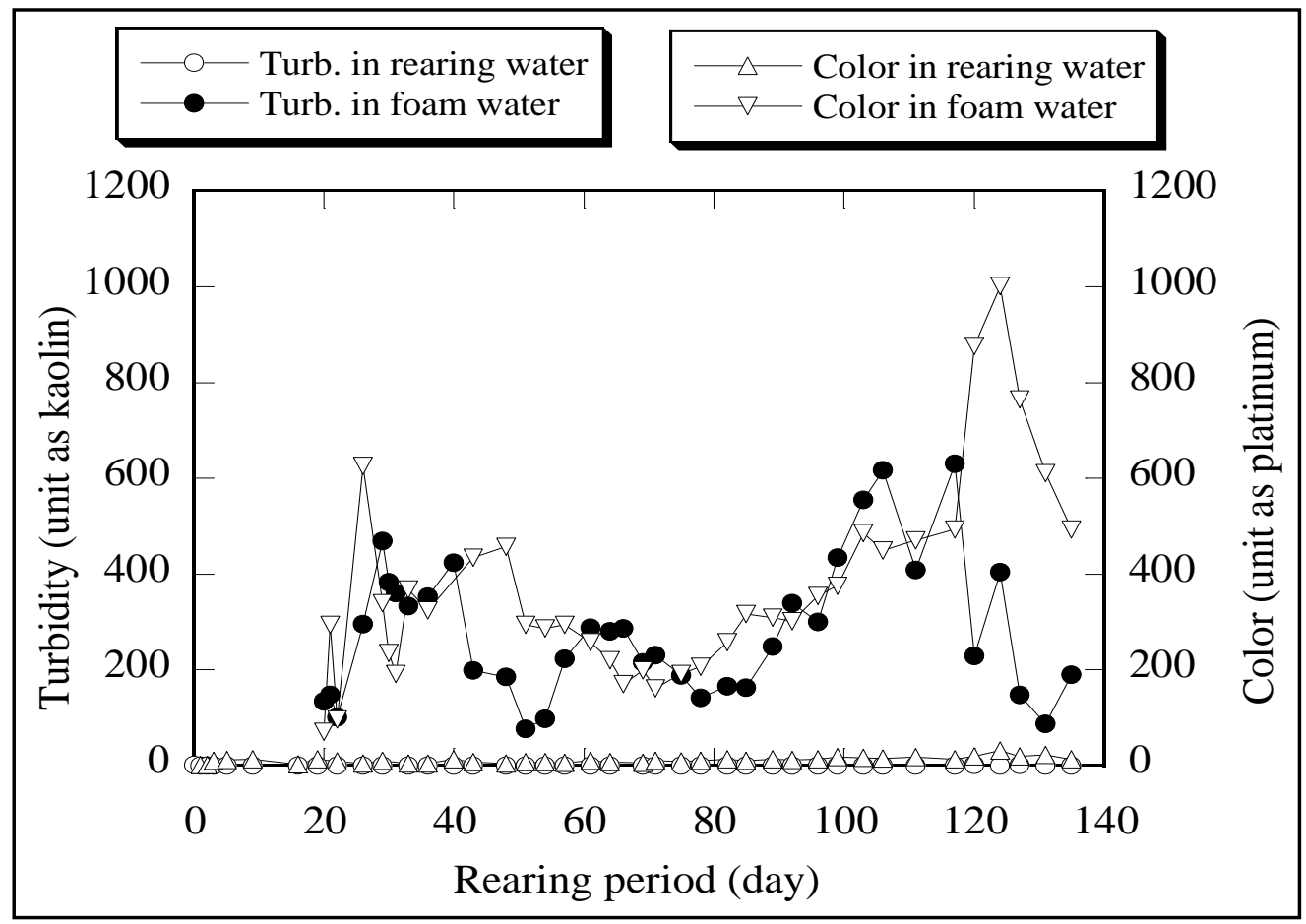

Fig. 5.Changes in turbidity and color in the rearing water and the foam water during the rearing period.

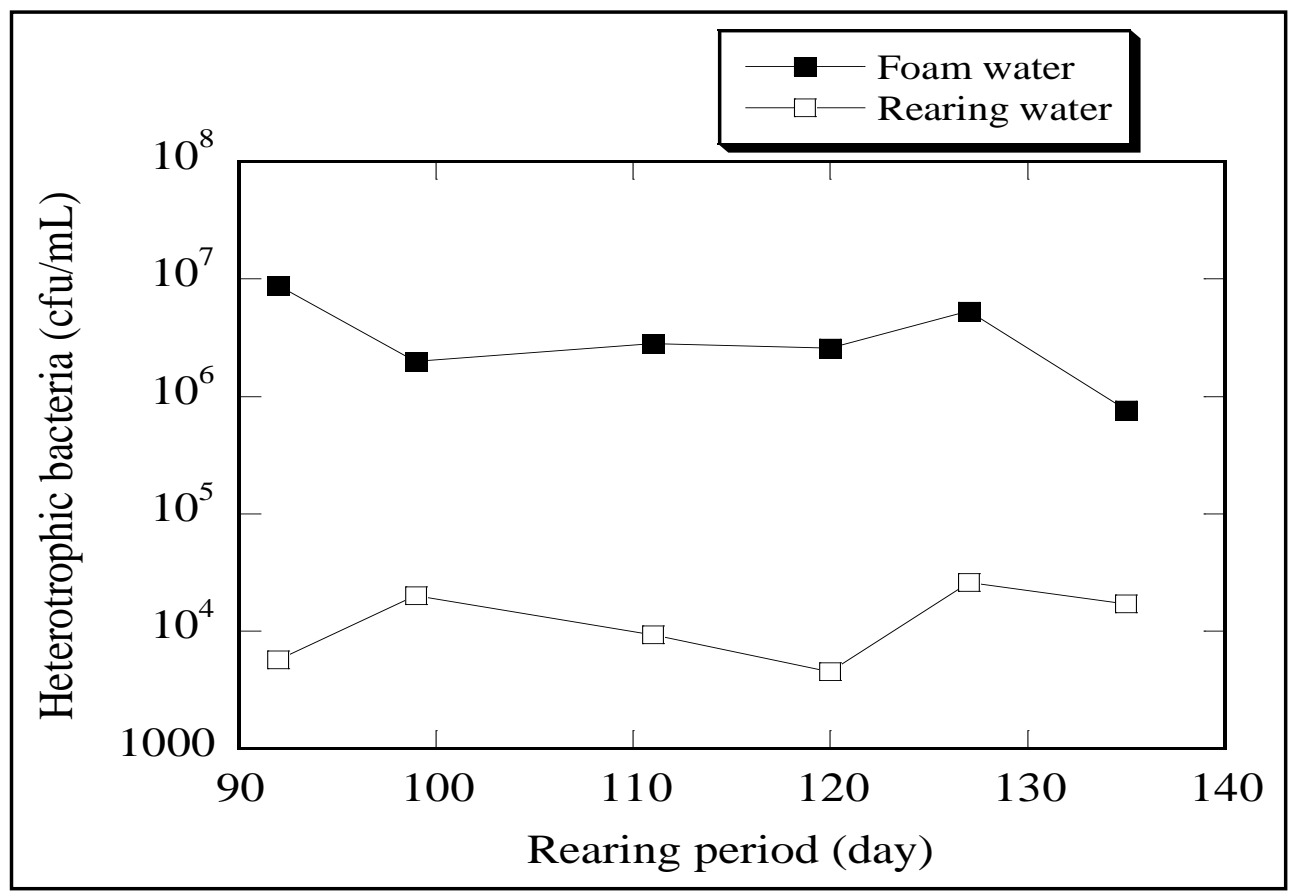

Fig. 6. Changes in bacteria counts in the rearing water and the foam water during the rearing period. 


\section{Mass balances}

About $25 \%$ of the total weight of feed remained in the system as suspended solids. The total of the residual amount of SS was considered as $100 \%$. The total $\mathrm{N}$ and $\mathrm{P}$ contents in the feed were considered as $100 \%$. The mass balances of this system for $\mathrm{SS}, \mathrm{N}$ and $\mathrm{P}$ are shown in Fig. 7. The $\mathrm{N}$ and $\mathrm{P}$ contents in the dried feed were $9.4 \%$ and $1.5 \%$, respectively. The $\mathrm{N}$ and $\mathrm{P}$ contents in the shrimp body were $11.7 \%$ and $1.0 \%$, respectively.

In the case of the SS, about $60 \%$ was accumulated in the nitrification tank and $5.9 \%$ was removed by foam separation (Fig. 7a). The nitrification tank functioned as both nitrification and sedimentation units. The point to be noticed is that the accumulation of SS in the sand was small, less than 3\%. In general, a huge amount of labor is needed for cleaning and maintenance of the sand in the shrimp culture tank. With the upflow type of rearing tank, it is possible to drastically ease the maintenance of rearing tank or pond for shrimp culture.

In the case of total nitrogen, 51\% was utilized for shrimp growth, 3.1\% was accumulated in the rearing water as $\mathrm{NO}_{3}-\mathrm{N}$ and organic nitrogen, $2.2 \%$ was removed by foam separation and $9.5 \%$ was accumulated in the nitrification and denitrification tanks as sediment (Fig. 7b). Regarding mass balances in the culture, the assimilation of nitrogen in the fish body varied from 25 to $35 \%$ of the total nitrogen input irrespective to the difference in fish species (Folke and Kautsky 1989; Hall et al. 1992; Maruyama and Suzuki 1998; Skjølstrup et al. 1998; Suzuki et al. 1999). The nitrogen assimilation in shrimp was higher than that in fish. Almost all the nitrogen that must be treated in this system was present as a dissolved fraction. In this study, the remaining $34.2 \%$ of nitrogen in the system was removed as nitrogen gas by denitrification. Denitrification could have removed the residual $\mathrm{NO}_{3}-\mathrm{N}$ in the rearing water if the operation was continued for a few days after the shrimp was harvested.

In the case of phosphorus, $27 \%$ was utilized for shrimp growth, 5\% was accumulated in the rearing water, $2.1 \%$ was removed by foam separation and $60 \%$ was accumulated in the nitrification and denitrification tanks as sediment (Fig. 7c). Because of analytical error, the total percentage exceeded $100 \%$. In case of a recirculating aquaculture system for sea fish, it has been reported that the phosphorus accumulates in high concentration in the sludge, because the phosphorus reacted with calcium and magnesium in the sea water and formed insoluble compounds (Suzuki et al. 2000). 


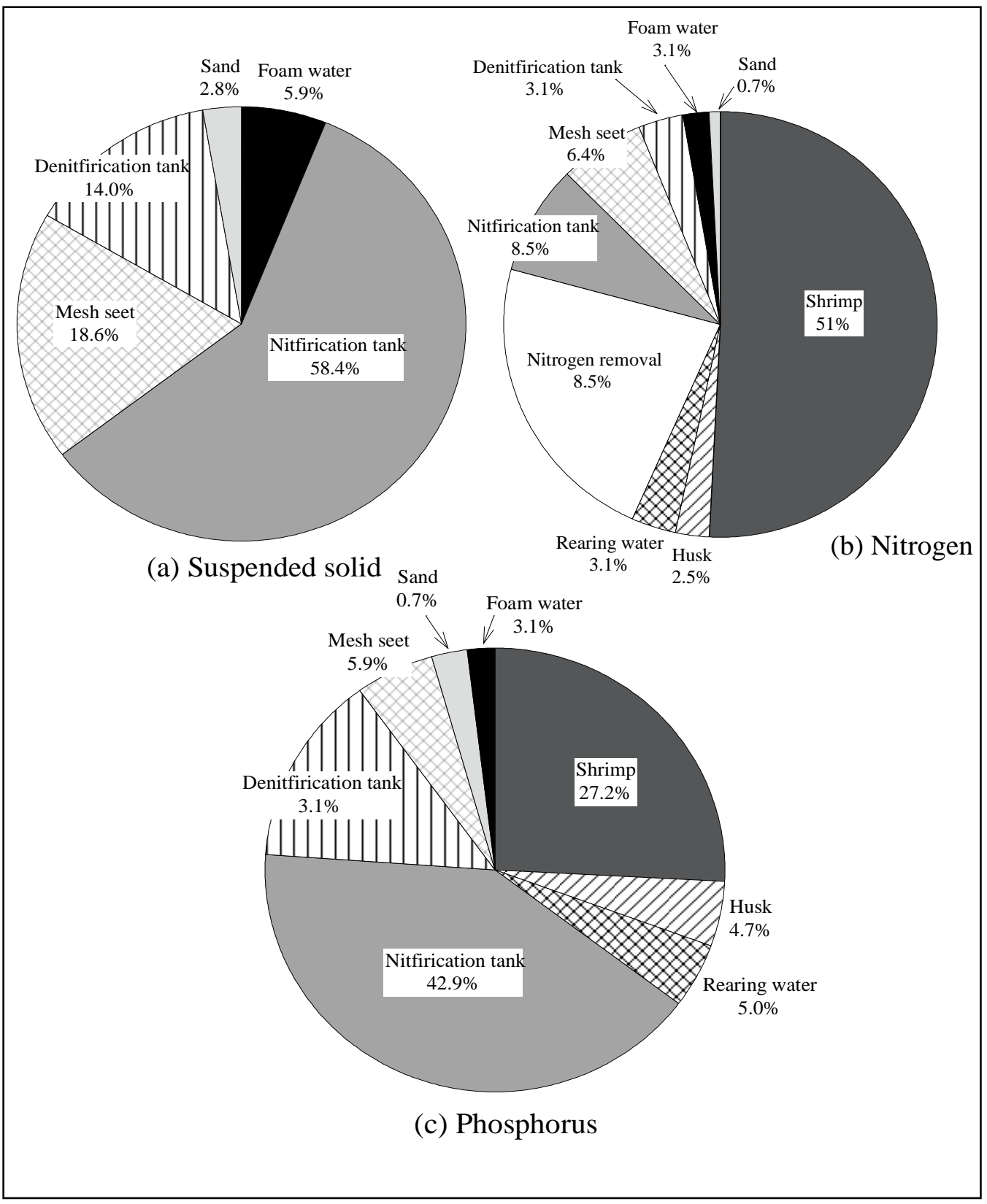

Fig. 7. Mass balances of suspended solid (a) nitrogen (b) and phosphorus (c) in the closed recirculating system. 


\section{Conclusions}

Our proposed system achieved kuruma shrimp culture in a perfectly closed cycle for more than 4 months. Shrimp growth was satisfactory and the average weight of individual increased more than ten-fold during the study period. Oxygen was efficiently supplied to the rearing water by a foam separation unit and oxygen saturation was maintained at $100 \%$ throughout the experiment. Simultaneously, the foam separation process removed the brown colloidal substances generated by shrimp mucus. The nitrification tank removed suspended solids and likewise rapidly nitrified TAN. While $\mathrm{NO}_{3}-\mathrm{N}$ accumulated in the rearing water in the absence of denitrification, after it was initiated on the 78th day, $\mathrm{NO}_{3}-\mathrm{N}$ was effectively removed and reduced to less than $4 \mathrm{mg}-\mathrm{N} \cdot \mathrm{L}^{-1}$ at the end of the study.

In this study, the rearing trial serves as a starting point. Further development to improve the low survival, to increase stocking density and shrimp growth rate and to minimize the capital and operating costs of this system will be necessary prior to potential commercial viability. This system has an application potential for production of kuruma shrimp under a perfectly closed rearing condition free of WSDV. Furthermore, the closed recirculating system can be utilized for maintaining pathogen free broodstocks since this system makes it easy to control the condition of a specific pathogen free environment.

\section{Acknowledgement}

This work was supported in part by grants from the Research and Development Program for New Bio-industry Initiatives, Japan.

\section{References}

Arbiv, A. and J. van Rijn. 1995. Performance of treatment system for inorganic nitrogen removal in intensive aquaculture systems. Aquacultural Engineering 14:189-203.

Blancheton, J.P. 2000. Developments in recirculation systems for Mediterranean fish species. Aquacultural Engineering 22:17-31.

Bovendeur, J., E.H. Eding and A.M. Henken. 1987. Design and performance of water recirculation system for high-density culture of the African catfish, Clarias gariepinus (Burchell 1822). Aquaculture 63:329-353.

Folke, C. and N. Kautsky. 1989. The role of ecosystems for a sustainable development of aquaculture. Ambio 18:234-243.

Geiner, A.D. and M.B. Timmous. 1998. Evaluation of the nitrification rates of microbead and trickling filter in an intensive recirculating tilapia production facility. Aquacultural Engineering 18:189-200. 
Hall, P.O.F., O. Holby, S. Kollberg and M. Samuelsson. 1992. Chemical fluxes and mass balances in a marine fish cage farm. IV. Nitrogen. Marine Ecology Progress Series 89:81-91.

Heinsbroek, L.T.H. and A. Kamsta. 1990. Design and performance of water recirculation systems for eel culture. Aquacultural Engineering 9:187-207.

Honda, H., Y. Watanabe, K. Kikuchi, N. Iwata, S. Takeda, H. Uemoto, T. Furuta and M. Kiyono. 1994. High density rearing of Japanese flounder, Paralichthys olivaceus with a closed seawater recirculation system equipped with a denitrification unit. Suisanzoushoku 41:19-26 (in Japanese, with English abstract).

Knosche, R. 1994. An effective biofilter type for eel culture in recirculating system. Aquacultural Engineering 13:71-82.

Kono, T., R. Savan, M. Sakai and T. Itami. 2004. Detection of white spot syndrome virus in shrimp by loop-mediated isothermal amplification. Journal of Virological Methods 115:59-65.

Maruyama, T., M. Okuzumi, A. Saheki and S. Shimamura. 1991. The purification effect of the foam separating system in living fish transportation and preservation. Nippon Suisan Gakkaishi 57:219-225 (in Japanese, with English abstract).

Maruyama, T., M. Okuzumi and Y. Satoh. 1996. The purification of rearing seawater of Japanese flounder with the closed foam separation-filtration system. Nippon Suisan Gakkaishi 62:578-585 (in Japanese, with English abstract).

Maruyama, T. and Y. Suzuki. 1998. The present stage of effluent control in Japan and pollutant load from fish culture to environment.-Possibility of intensive recirculating fish culture systems-. Nippon Suisan Gakkaishi 64:216-226 (in Japanese, with English abstract).

Maruyama, T., Y. Suzuki, D. Sato, T. Kanda and T. Michisita. 1998. Performance of a closed recirculating system with foam-separation and nitrification units for intensive culture of Japanese flounder. Nippon Suisan Gakkaishi 65:818-825 (in Japanese, with English abstract).

Mumby, P.J., A.J. Edwards, J.E. Arias-Gonzalez, K.C. Lindeman, P.G. Blackwell, A. Gall, M.I. Gorczynska, A.R. Harborne, C.L. Pescod, H. Renken, C.C.C. Wabniz and G. Llewellyn. 2004. Mangroves enhance the biomass of coral reef fish communities in the Caribean. Nature 427:533-536.

Ng, W.J., K. Kho, L.M. Ho, S.L. Ong, T.S. Sim, S.H. Tay, C.C. Goh and L. Cheong. 1992. Water quality within a recirculating system for tropical ornamental fish culture. Aquaculture 103:123-134.

Otoshi, C.A., S.M. Arce and S.M. Moss. 2003. Growth and reproductive performance of broodstock shrimp reared in a biosecure recirculating aquaculture system versus a flowthrough pond. Aquacultural Engineering 29:93-107.

Van Rijn, J. and G. Rivera. 1990. Aerobic and anaerobic biofiltration in aquaculture unit -Nitrate accumulation as a result of nitrification and denitrification. Aquacultural Engineering 9:217-234.

Van Rijn, J. 1996. The potential for integrated biological treatment systems in recirculating fish culture - a review. Aquaculture 139:181-201.

Skjølstrup, J., P.H. Nielsen, F.O. Frier and E. McLean. 1998. Performance characteristics of fluidized bed biofilters in a novel laboratory scale recirculation system for rainbow trout: nitrification rates, oxygen consumption and sludge collection. Aquacultural Engineering 18:265-276. 
Suzuki, Y., T. Maruyama, S. Takemoto and R. Oda. 1999. Performance of a closed recirculating system with foam separation, nitrification and denitrification units for the intensive culture of eel. Journal of Japan Society on Water Environment 22:896-903 (in Japanese, with English abstract).

Suzuki, Y., T. Maruyama, D. Sato, T. Kanda and T. Michisita. 2000. Water quality and mass balances in a culture of Japanese flounder using a closed recirculation system with foam-separation and nitrification units. Nippon Suisan Gakkaishi 66:1-9 (in Japanese, with English abstract).

Suzuki, Y., T. Maruyama, H. Numata, H. Sato and M. Asakawa. 2003. Performance of a closed recirculating system with foam separation, nitrification and denitrification units for the intensive culture of eel: towards zero emission. Aquacultural Engineering 29:165-182.

Yoshino, H., D.E. Gruenberg, I. Watanabe, K. Miyajima and O. Satoh. 1999. Changes in water quality and performance of a closed recirculating seawater aquaculture system for rearing pejerrey, Odonthestes bonariensis. Suisanzoushoku 47:289-297 (in Japanese, with English abstract). 